\title{
Spring Serenade
}

\section{HAL G. DUNCAN, Boissevain, Man.}

Dawn is breaking in the east. Light streamers shoot up into the dark dome of the sky like flickering wands. The hush of night is stirred by a soft, gentle breeze as darkness steals quietly away before the promise of a new day.

On a slight, bare rise bordering a sweeping marsh shadowy forms gather on silent wing. Suddenly a deep, hollow boom, boom, b-o-o-m rolls out over the awakening plains: vibrant and pulsating it quivers away through the clear, limpid air with the stirring quality of battle drums. From somewhere to the east or west or north or south, a half mile, a mile, two miles there rolls back an answering boom, boom, $\mathrm{b}-\mathrm{o}-\mathrm{o}-\mathrm{m}$. Again and again the resonant notes, both challenging and promising, stir the accrescent dawn. It is the drumming of the Pinnated Grouse. Spring has arrived on the prairies.

Year after year when spring pushes winter away to its northern retreat the "Prairie Chicken" gather ir their elaborate mating dances. A bare knoll or a spot with very short grass is used year after year for the larger gatherings. The first arrivals settle quietly on the selected spot and stand like sentinels, keen eyes searching for a lurking enemy. Then a hen bird utters a few low, clucking notes; another answers, querulous, tentative sounds. Then a cock bird stretches, his tail fans out and up over his back. The sacs on his neck puff and swell and the stiff, feather ruffs begin to rise up over his head. A low, soft $\mathrm{b}-\mathrm{o}-\mathrm{o}-\mathrm{m}$ dies in his throat, to be followed by another and another, each of increasing volume. By now the spirit of battle is full upon him, the sacs extend till they resemble small oranges on either side of his neck and the full, intense booming of the cock "Prairie Chicken" rolls out.

From many points the challenge is accepted and rivals arrive on bullet-like wings. In a few minutes a half dozen pitched battles are in progress. Feathers float to the ground as the adversaries leap high in the air, striking with their wings and pecking viciously with their short beaks. Meanwhile, others not engaged in combat strut and pose before the hen birds and keep up a continuous drumming as though urging contestants to greater efforts. The flash and thump of striking wings, the continual arrival of those fresh for the dance and the departure of the vanquished gives a shifting, kaleidoscopic effect to an unforgettable scene.

As a boy none of the notes of the symphony of song poured out by the prairie feathered folk in their spring happiness stirred me like the booming of the "Prairie Chicken" during their mating rituals. Many times in years past I have lain in the grass along the edge of Whitewater Lake and thrilled to the action and sound as I watched the "Prairie Chicken" dance on one of their favorite places on the lakeshore.

The mating dance of the Pinnated Grouse is unique amongst birds and those who have seen it are fortunate, for unless this fine bird can make an unprecedented recovery from its present very low ebb it is doomed to follow the others of our birds that have become extinct through lack of protection from over hunting and the careless destruction of their habitat without thought for the future. Then, I and others, will strain our ears in vain for the drumming of the Prairie Chicken in their spring serenade.

\section{SUMMER MEETING}

On June 9 and 10, 1956, the Saskatchewan Natural History Society extends a cordial invitation to members and friends to meet at Madge Lake. The roads and accommodation at Madge Lake are good. The lake is in the northern forest zone with lots of evergreens. Plan now to join us at Madge Lake and spend two days making new friends and learning something more about our native plants and animals. Write to Mr. W. Yanchinski, Naicam for reservations. 